\title{
Solitary pulmonary metastasis from primary melanoma of the oesophagus 5 years after resection of the primary tumor
} \author{
Gianlorenzo Dionigi*1, Francesca Rovera ${ }^{1}$, Luigi Boni ${ }^{1}$, Andrea Imperatori ${ }^{2}$ \\ and Renzo Dionigi ${ }^{1}$
}

Address: ${ }^{1}$ Department of Surgical Sciences, University of Insubria, Varese, Italy and ${ }^{2}$ Center for Thoracic Surgery, University of Insubria, Varese, Italy

Email: Gianlorenzo Dionigi* - gianlorenzo.dionigi@uninsubria.it; Francesca Rovera - francesca.rovera@uninsubria.it;

Luigi Boni - luigi.boni@uninsubria.it; Andrea Imperatori - andrea.imperatori@uninsubria.it; Renzo Dionigi - renzo.dionigi@uninsubria.it

* Corresponding author

Published: 13 April 2006

World Journal of Surgical Oncology2006, 4:22 doi:10.1186/1477-7819-4-22

This article is available from: http://www.wjso.com/content/4/I/22

(C) 2006Dionigi et al; licensee BioMed Central Ltd.

This is an Open Access article distributed under the terms of the Creative Commons Attribution License (http://creativecommons.org/licenses/by/2.0), which permits unrestricted use, distribution, and reproduction in any medium, provided the original work is properly cited.
Received: 3I October 2005

Accepted: 13 April 2006

\begin{abstract}
Background: Primary malignant melanoma of the oesophagus (PMME) is an uncommon tumor. PMME has an aggressive biological behavior, similar to melanomas developed elsewhere in the body. Most patients die from distant metastases, and the overall 5 year survival rate is approximately $4 \%$.
\end{abstract}

Case presentation: We report a rare case of a solitary pulmonary metastasis found 5 years after curative resection of primary esophageal melanoma. No other sites of metastatic disease were identified. Video-assisted lung wedge resection of the lung nodule was carried out successfully.

Conclusion: This supports the concept that patients with primary melanoma of the oesophagus treated should be carefully followed up.

\section{Background}

Primary melanoma of the oesophagus (PMME) is an uncommon tumor with an incidence of $0.1 \%$ of esophageal cancer and represents about $0.5 \%$ of noncutaneous melanomas [1]. Firstly Baur reported a case in 1906 [2]. PMME was not widely accepted until de la Pava in 1963 demostrated the presence of melanocytes in normal oesophageal mucosa in 4 of 100 normal esophagus at autopsy examination. Tateshi reported an incidence of $8 \%$ for the presence of melanocytes in the stratum basale of normal esophagi of Japanese subjects [4]. Although the presence of normal melanocytes in the esophagus has been largely demonstrated, their origin is still debatable [3]. Suzuki in a large study on surgical and autopsied specimens reported a $0.1 \%$ and $0.14 \%$ incidence respectively
[5]. Two-hundreds cases are described in literature. Almost $90 \%$ of PMME are located in the lower third of the esophagus and melanosis seems to be a predisposing factor since it as been found in almost $25 \%$ of the patients suffering for PMME [6]. Diagnosis is made by exclusion criteria with no other primary cutaneous, ocular, mucosal lesion detected. Histologically, the tumor is considered as primary when it presents with a characteristic structure of melanoma and contains pigment (melanin), neighboring melanosis or melanocytic dysplasia is generally required to distinguish it from metastatic disease, the tumor is often polypoid and arise in an area of junctional changes in the squamous epithelium [7]. Histopathological examination is usually mandatory to reach a definitive diagnosis since symptoms are not different from those of other 


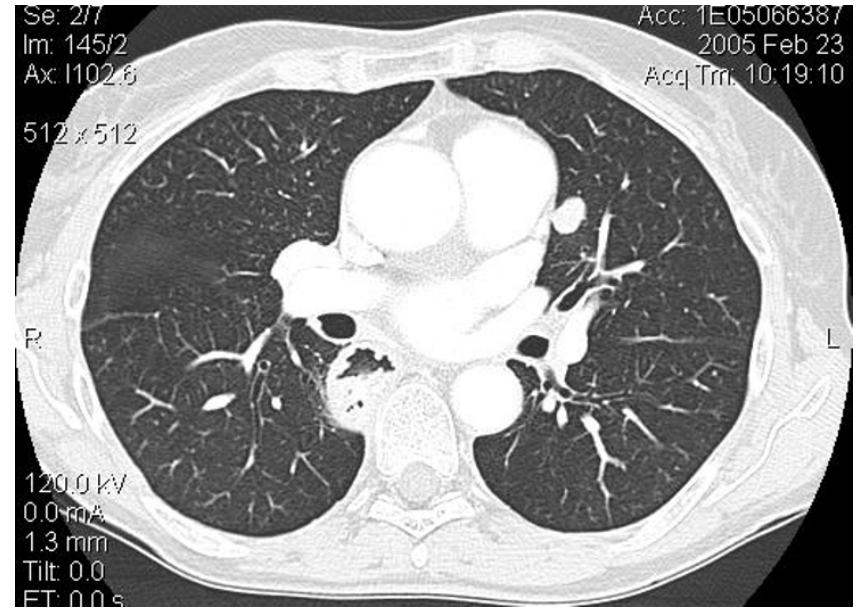

Figure I

Computed tomography: well delimited pulmonary nodule of $13 \mathrm{~mm}$ in diameter of the LUL.

malignant tumors of the esophagus. It is associated with a poor survival, also when resected at an early stage. In fact the tumor has an aggressive biological behavior, similar to melanomas occurred elsewhere in the body. Most patients die from distant metastases, and the 5 year survival rate is approximately $4 \%$. At the time of presentation, $40 \%$ of patients have already metastatized, primarily to regional lymph nodes, liver, lung, or bones [8]. Although pulmonary metastasis from melanoma is not uncommon, the case we report of a solitary pulmonary metastasis found 5 years after curative resection of the primary esophageal tumor is extremely unusual $[9,10]$. A review of recent literature is also presented.

\section{Case presentation}

A 62-year-old caucasian woman, who had undergone curative resection of primary melanoma of the oesophagus 5 years earlier without adjuvant chemo-radiotherapy $[9,10]$, was referred to our hospital for a solitary pulmonary nodule $(13 \times 10 \mathrm{~mm})$ in the left upper lobe (LUL) detected during routine follow-up chest X-ray examination. Thoracic computed tomography (CT) showed a well delimited round tumor, about $13 \mathrm{~mm}$ in diameter located in the LUL, with no mediastinal lymph-nodes enlargement (Figure 1); brain and abdominal CT performed for staging did not find distant metasteses. Staging was then compleated with flexible endoscopy (the remnant esophagus, stomach and duodenum were normal), immunoscintigraphy with 99 mTc-labeled melanoma monoclonal, bone scan and broncoscopy which resulted all negative. Laboratory tests were unremarcable. Video-assisted lung wedge resection of the pulmonary nodule was carried out successfully. A definitive pathological diagnosis was achieved: the macroscopic examination of the surgical specimen confirmed the CT findings. The final histology confirmed proliferation of small spindle-shaped or stellate cells arranged in a spiral or fascicular structure, the tumor cells were intesively positive for immuno-reaction, using HMB45 anti-melanoma antibodies (Figure 2, 3). These findings were compatible with the diagnosis of metastases of primary esophageal melanoma. The patient had an uneventful postoperative course and is still well without any evidence of further recurrence 6 months after surgery. This is a rare case of solitary lung metastasis appearing 5 years after eradication of primary esophageal melanoma.

\section{Discussion}

Several explanations have been postulated for delayed metastasis of differentiated tumors. Alexander presented an intriguing pathogenic hypothesis proposing that clusters of dividing cells lead to an equilibrium between cell death and proliferation, or that the tumor cells remain in a state of rest for long periods without losing their viability before renewed tumor growth is induced by the somatic transformation of the cancer cells [11]. We report a rare case of a solitary pulmonary metastasis found 5 years after curative resection of primary esophageal melanoma. Radical surgical resection with en bloc lymphadenectomy is the treatment of choice of primary melanoma of the oesophagus, with a five year survival of $4.25 \%$ [8]. Although laser, radiotherapy, chemotherapy, immunotherapy have not proven to be beneficial, they may play a palliative role if surgery is not applicable for advanced stages or poor functional status [12]. Of the approximately 200 cases that have been reported to date, only about $30 \%$ of the patients survived more than 1 year after the initial diagnosis [8]. The aggressive biological behavior of this disease, the advanced stage at the time of

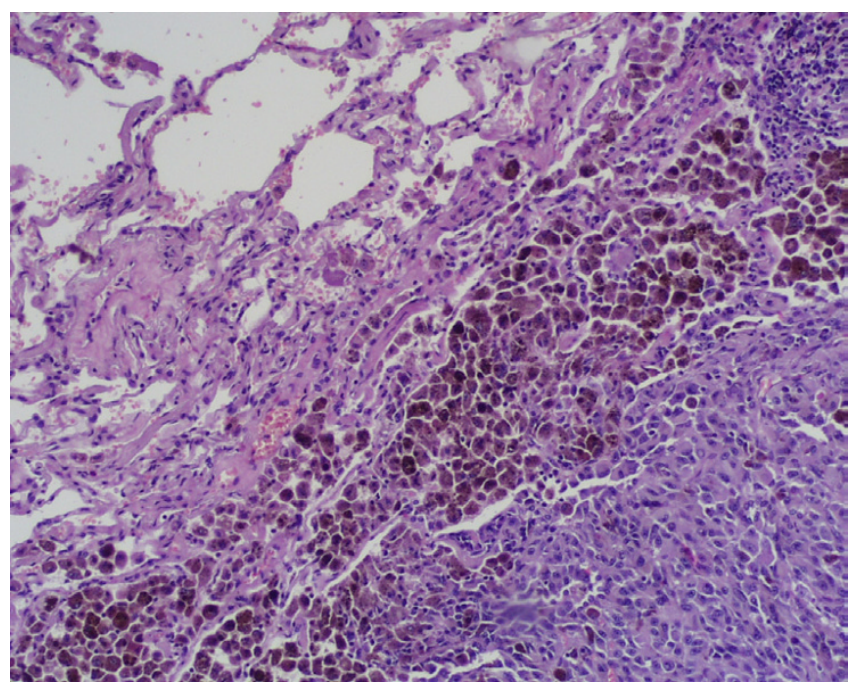

\section{Figure 2}

Histology: section through pulmonary tissue showing metastatic melanoma (hematoxylin and eosin x40 and x100). 


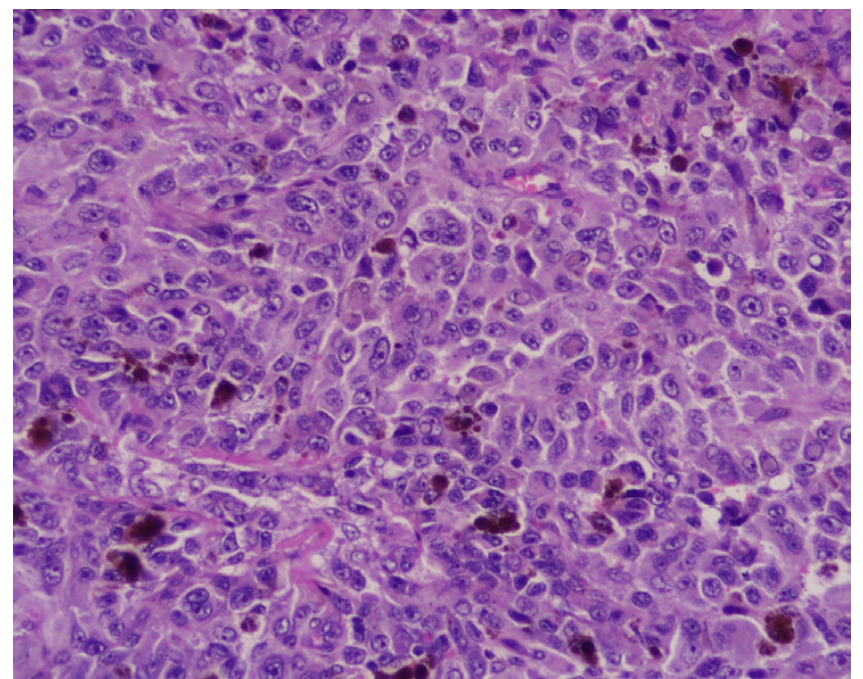

Figure 3

The tumor cells are intesively positive for immuno-reaction, using HMB45 anti-melanoma antibodies.

diagnosis and the lack of effective therapy contribute to its poor prognosis. PMME is a very aggressive tumor and esophagogastroduodenoscopy, endoscopic ultrasonography and CT scan are required to complete the preoperative staging. Chalkiadakis demonstrated that distant metastases are present in $78 \%$ of the patients suffering from PMME [13]. The most common site of metastases is the liver $(31 \%)$, followed by mediastinum (29\%), lung $(17 \%)$, brain $(13 \%)$ and other intra-abdominal organs. Detection rate of metastatic disease identification using immunoscintigraphy with 99 mTc-labeled melanoma monoclonal $\mathrm{AB}$ is $95 \%$ for bone lesions, $91 \%$ for liver, $78 \%$ for lymph node metastases, $62 \%$ for brain, $62 \%$ for spleen and $58 \%$ for lung $[14,15]$. This technique cannot identify deposits of $1 \mathrm{~cm}$ or less in size [14,15]. Although it has been demonstrated that radical resection increases the survival compared to local treatment, 5-year survival is less than 5\%, mainly due to the advanced state of the disease at the time of diagnosis [16]. Various drugs, alone or in combination, including vinblastine, bleomycin, lomustine, vincristine and recently recombinant interferon-alpha and interleukin-2, have been used with varying results as palliative treatment of cutaneous melanoma [17-20]. Combination of cisplatin, carmustine, dacarbazine and tamoxifen have also been studied with promising results in cutaneous melanoma patients with advanced disease [21]. Several investigators have supported the above findings and the role of tamoxifene as drugs modulator [22-24]. Nevertherless, none of these regimens have been used in esophageal melanomas which is considered to be a radioresistant tumor, and chemotherapy, external beam and intracavitary radiotherapy may only have a palliative role [25]. At the time of diagnosis, clinically, surgically or pathologically detectable metastases were present in $40.9 \%$ of patients. The overall survival is 9.8 months with five year survival rate of $1.69 \%$. Only $33 \%$ of patients survive for more than 1 year after diagnosis. Deaths are disease-related in $75-85 \%$ of cases [8].

Although the reason for the delayed presentation of the metastatic lesion remains unclear, the case report we described demonstrates that patients with primary melanoma of the oesophagus surgically treated should be carefully followed up.

\section{Competing interests}

The author(s) declare that they have no competing interests.

\section{Authors' contributions}

GD: acquisition of data, FR: study conception and design, LB: analysis and interpretation of data, GD, AI: drafting of manuscript, RD: Critical revision and supervision

\section{Acknowledgements}

Written consent of the patient was obtained for publication of this case report

\section{References}

I. Cadwell CB: Unusual malignant neoplasm of the esophagus. J Thorac Cardiovasc Surg 1991, 101:100-107.

2. Baur EH: Ein Fall von primarem melanom des esophagus. Arb Geb Pathol Anat Inst Tubingen 1906, 5:343-354.

3. De la Pava S, Nigogosyan G, Pickren JW, Cabrera A: Melanosis of the esophagus. Cancer 1963, 16:48-50.

4. Tateshi R: Argyophil cells and melanocytes in esophageal mucosa. Arch Pathol 1997, 98:87-89.

5. Suzuki H, Nagayo T: Primary tumor of the esophagus other than squamous cell carcinoma: histological classification and statistics in the surgical and autopsied material in Japan. Int Adv Surg Oncol 1980, 3:73-109.

6. Di Costanzo DP, Urmacher C: Primary malignant melanoma of the esophagus. Am J Surg Pathol 1987, I I:46-52.

7. Allen AC, Spitz S: Malignant melanoma: a clinicopathological analysis of the criteria for diagnosis and prognosis. Cancer 1953, 6: I-45.

8. Sabanathan S, Eng J, Pradhan GN: Primary malignant melanoma of the esophagus. Am J Gastroenterol 1989, 84: 1475-I48I.

9. Boni L, Benevento A, Dionigi G, Dionigi R: Primary malignant melanoma of the esophagus: a case report. Surg Endosc 2002, 16:359-360.

10. Boni L, Benevento A, Cabrini L, Dionigi G, Dionigi R: Primary melanoma of the esophagus. J Am Coll Surg 2002, 1 94:840.

II. Alexander P: Dormant metastases - studies in experimental animals. J Pathol 1983, 141:379-383.

12. Lin CY: Primary malignant melanoma of the oesophagus presenting with massive melena and hypovolemic shock. ANZ J Surg 2002, 72:62-64.

13. Chalkiadakis G, Wihlm JM, Morand G, Weill-bousson M, Witz JP: Primary malignant melanoma of the esophagus. Ann Thorac Surg 1985, 39:472-475.

14. Salk D: Technetium-labeled monoclonal antibodies for imaging metastatic melanoma: results of a multicenter clinical study. Semin Oncol 1988, 15:608-618.

15. Lamki LM, Zukiwski AA, Shanken LJ: Radioimaging of melanoma using $99 \mathrm{mTc}$-labeled Fab fragment reactive with a high molecular weight melanoma antigen. Cancer Res 1990, 50:904-908. 
16. Hamdy FC, Smith JFH, Kennedy A, Thorpe JAC: Long survival after excision of primary malignant melanoma of the oesophagus. Thorax 1991, 46:397-398.

17. Philip PA, Flaberty L: Treatment of malignant melanoma with interleukin-2. Semin Oncol 1997, 24:S32-S38.

18. Rusciani L, Petraglia S, Alotto M, Calvieri S, Vezzoni G: Postsurgical adjuvant therapy for melanoma Evaluation of a 3-year randomized trial with recombinant interferon-alpha after 3 and 5 years of follow-up. Cancer 1997, 79:2354-2360.

19. Seigler HF, Lucas V, Pickett NJ: DTIC, CCNU, bleomycin and vincristine. Cancer 1980, 46:2346-2348.

20. York RM, Foltz A: Bleomycin, vincristine, lomustine and DTIC chemotherapy for metastatic melanoma. Cancer 1988, 6I:2183-2186.

21. Del Prete SA, Maurer LH, O'Donell J, Forcier RJ, LeMarbre P: Combination chemotherapy with cisplatin, carmustine, dacarbazine and tamoxifen in metastatic melanoma. Cancer Treat Rep 1984, 68: I 403-I 405.

22. Mc Clay EF, Mastrange MJ, Berd D, Bellet RE: Effective combination chemo/hormonal therapy for malignant melanoma; experience with three consecutive trials. Int J Cancer 1992, 50:553-556

23. Mills SE, Cooper $\mathrm{PH}$ : Malignant melanoma of the digestive system. Pathol Annu 1983, 18:1-26.

24. Saba HI, Cruse CW, Wells KE, Klein CJ, Reintgen DS: Treatment of stage IV malignant melanoma with dacarbazine, carmustine, cisplatin and tamoxifen regimens: a University of South Florida and H. Lee Moffitt Melanoma Center study. Ann Plast Surg 1992, 28:65-69.

25. Jawalekar K, Tretter P: Primary malignant melanoma of the esophagus. J Surg Oncol 1979, I 2:19-25.

Publish with Bio Med Central and every scientist can read your work free of charge

"BioMed Central will be the most significant development for disseminating the results of biomedical research in our lifetime. "

Sir Paul Nurse, Cancer Research UK

Your research papers will be:

- available free of charge to the entire biomedical community

- peer reviewed and published immediately upon acceptance

- cited in PubMed and archived on PubMed Central

- yours - you keep the copyright 